\title{
Disaster linguicism: Linguistic minorities in disasters
}

\author{
S H I N Y A U E K U S A \\ University of Auckland, New Zealand
}

\section{A B S T R A C T}

Language is a means of communication but it functions as much more than this in social life. In emergencies and disasters, it can also be a matter of life and death. Language barriers and effective communication in disaster contexts (i.e. distributing critical disaster information and warnings) are the central concern in current disaster research, practice, and policy. However, based on the data drawn from qualitative interviews with linguistic minority immigrants and refugees in Canterbury, New Zealand and Miyagi, Japan, I argue that linguistic minorities confront unique disaster vulnerability partly due to linguicism - language-based discrimination at multiple levels. As linguicism is often compounded by racism, it is not properly addressed and analyzed, using the framework of language ideology and power. This article therefore introduces the concept of disaster linguicism, employing Pierre Bourdieu's concept of symbolic violence, to explore linguistic minorities' complex disaster experiences in the 2010-2011 Canterbury and Tohoku disasters. (Disaster linguicism, language barriers, language ideologies)*

\section{N T R O D U C T I O N}

Language is a means of communication, but there is a dominant language in any social space such that Bourdieu \& Passeron (1977:73) argue that language or linguistic capital functions as more than just a means of communication in our social life. In disasters ${ }^{1}$ (which are consequences of both natural and anthropogenic hazard events such as earthquakes, floods, wars, and mass emergencies), language barriers can be a matter of life and death. Although such barriers and effective communication during disasters (i.e. distributing critical disaster information and warnings) are of central concern in current disaster research, practice, and policy, linguistic minorities are understudied, and their disaster experiences are not as simple as many of us believe. Based on data drawn from qualitative interviews I have conducted with linguistic minority immigrants and refugees in Canterbury, Aotearoa New Zealand and Miyagi, ${ }^{2}$ Japan, it can be said that linguistic minorities confront unique disaster vulnerability partly due to linguicism - language-based discrimination at structural as well as interpersonal levels. Previous research emphasized the exclusion and disadvantages that linguistic minorities confronted in the 2011 Great East Japan Earthquake and Tsunami (hereinafter the Tohoku 
disasters) and other disasters (see e.g. Tan \& Said 2015). However, as linguicism is often compounded by racism (Phillipson 1992; Uekusa 2009), it is often not properly addressed and analyzed in disaster research, using the framework of language ideology and power. This cross-national study delves into the concept of disaster linguicism. Employing Pierre Bourdieu's concept of symbolic violence-hegemonic power or a soft form of 'violence which is exercised upon a social agent with his or her complicity' (Bourdieu \& Wacquant 1992:167; see also Bourdieu 1991), it explores linguistic minorities' rather complex disaster experiences in the 2010 Canterbury Earthquake and the 2011 Christchurch Earthquake (hereinafter the Canterbury disasters), and the 2011 Tohoku disasters.

S T U D Y B A C K G R U N D : THE 2010-2011

DISASTERS AND LINGUISTIC MINORITIES

As details of the Canterbury and Tohoku disasters are available elsewhere, this article does not elaborate the seismic activities that occurred in these two locations and their subsequent impacts (see e.g. Kazama \& Noda 2012 and Potter, Becker, Johnston, \& Rossiter 2015 for details). These natural hazard events triggered significant economic, physical, and social impacts on the wider Canterbury and Tohoku regions - the central part of New Zealand's South Island and the northeastern coastal area of Japan. In the Canterbury Region, 185 fatalities (including a significant number of international students from Japan and other Asian countries) were reported due to the February 2011 earthquake, which struck the city center and caused some building collapses (see Otani 2016). Only a couple of weeks after the February earthquake, one of the deadliest earthquakes in Japan struck the eastern part of the country and triggered a series of thirty to forty foot tsunami, which devastated the Tohoku coastal communities and caused the Fukushima nuclear meltdown. As of December 2011, these triple disasters caused 15,844 fatalities and displaced twelve million residents (Suzuki 2012).

In these disasters, despite their small proportion (see Table 1), many linguistic minority migrants and refugees were affected. Linguistic minorities are typically considered more vulnerable than the general population partly because of language barriers and structural inequality (Donner \& Rodríguez 2008; Marlowe \& Bogen 2015), but, when compared to other socially vulnerable groups such as women, children, and the elderly, this particular group has been under-investigated. While refugee groups often receive localized disaster education by resettlement supporting organizations such as the Red Cross, some linguistic minorities such as voluntary migrants and transients may not possess sufficient linguistic competency and disaster knowledge in order to receive critical information and to protect themselves in the wake of disasters. In both locations, disaster warnings and announcements were only made in the de facto languages, English and Japanese respectively. 
TABLE 1. Disasters, languages, and demographics for each study location (Statistics New Zealand 2013; Ministry of Justice 2013).

\begin{tabular}{|c|c|c|c|c|c|c|c|c|}
\hline $\begin{array}{l}\text { Region, } \\
\text { Prefecture, } \\
\text { Country }\end{array}$ & Disaster agents & $\begin{array}{c}\text { Official } \\
\text { language(s) }\end{array}$ & $\begin{array}{l}\text { De facto } \\
\text { language }\end{array}$ & $\begin{array}{l}\text { Next common } \\
\text { languages (in } \\
\text { these locations) }\end{array}$ & $\begin{array}{c}\text { Population } \\
\text { (national) }\end{array}$ & $\begin{array}{l}\text { Oversea born } \\
\text { citizens and } \\
\text { residents } \\
\text { (national) }\end{array}$ & $\begin{array}{l}\text { Common } \\
\text { immigrant and } \\
\text { foreign born } \\
\text { groups }\end{array}$ & $\begin{array}{l}\text { Linguistic minorities } \\
\text { who self-reported not } \\
\text { speaking the dominant } \\
\text { language (national) }\end{array}$ \\
\hline $\begin{array}{l}\text { Canterbury, } \\
\text { New Zealand }\end{array}$ & $\begin{array}{l}\text { Earthquake } \\
\text { (M.6.2 in the } 2011 \\
\text { Earthquake) }\end{array}$ & $\begin{array}{l}\text { Te Reo Māori } \\
\text { NZ Sign Language }\end{array}$ & English & $\begin{array}{l}\text { Te Reo Māori } \\
\text { French } \\
\text { German } \\
\text { Samoan } \\
\text { Chinese }\end{array}$ & $\begin{array}{l}0.54 \text { million } \\
(4.7 \text { million })\end{array}$ & $\begin{array}{l}23.6 \% \\
(25 \%)\end{array}$ & $\begin{array}{l}\text { *Asian } \\
\text { British/Irish } \\
\text { *Pacific Islands }\end{array}$ & $\begin{array}{l}7.5 \% \\
(9.9 \%)\end{array}$ \\
\hline Miyagi, Japan & $\begin{array}{l}\text { Earthquake (M9.1), } \\
\text { tsunami, } \\
\text { nuclear meltdown }\end{array}$ & NA & Japanese & $\begin{array}{l}\text { Chinese } \\
\text { Korean } \\
\text { Tagalog } \\
\text { Portguese }\end{array}$ & $\begin{array}{l}2.3 \text { million } \\
\text { (127 million) }\end{array}$ & $\begin{array}{l}0.6 \% \\
(1.8 \%)\end{array}$ & $\begin{array}{l}\text { Chinese } \\
\text { Korean } \\
\text { Filipino/as }\end{array}$ & $\begin{array}{l}* * 0.6 \% \\
* *(1.8 \%)\end{array}$ \\
\hline
\end{tabular}

*These broad categories are used in 2013 New Zealand Census, instead of actual nationalities or ethnic/racial groups.

**Estimated based on the number of registered foreign nationals (official statistics are not available). 
Linguistic minorities in New Zealand and Japan are those who are not native speakers of the de facto languages and those who do not comprehend these languages. Official languages in New Zealand are Te Reo Māori and New Zealand Sign Language; however, the de facto language is English (Benton 2015). In turn, Japanese is the de facto language in Japan (Tan \& Said 2015). Except for Indigenous groups (e.g. Māori in New Zealand), most linguistic minorities in these locations are immigrants, refugees, and transients, who comprise small percentages in these regions. In both locations, linguistic minorities are small in number to start with (Table 1), and many may not even be included in the census (or other mainstream) data due to language barriers (see Klinenberg 2002). Thus, linguistic minorities may be more vulnerable to disasters, but this group is relatively invisible and consequently underinvestigated.

\section{LINGUICISM AND B OURDIEU'S SYMBOLIC V I O L E N C E}

The concept of linguicism was first introduced by Skutnabb-Kangas \& Phillipson, who define it as '[i]deologies, structures and practices which are used to legitimate, effectuate and reproduce an unequal division of power and resources (both material and non-material) between groups which are defined on the basis of language' (Phillipson 1992, quoted in Skutnabb-Kangas \& Phillipson 1995:105). Although their original concept of linguicism emphasizes language-related structural discrimination, such as limited governmental service access in minority languages, linguicism could be conceived as a form of discrimination based on language, which also operates at a micro-level (Uekusa 2009:1). In an extremely simple sense, linguicism is a form of discrimination based on language against linguistic minorities, operating at multiple levels such that it even includes people's discriminatory practices in everyday interpersonal interactions based on the intensity of one's accent (LippiGreen 1997; Woodrow 2006).

Like racism and sexism, linguicism is often institutionalized and intersects with other forms of discrimination to complicate the system of oppression (see Collins 2000 for intersectionality). For instance, one's educational success and access to education is typically dependent on one's primary language (Bourdieu 1991; Train 2007); language competency is required for employment and economic activities (Hakuta 1986); government services may only be available in dominant language(s) (Tierney 2006); political participation is limited for linguistic minorities (Schmid 2001); and linguicism is compounded with other forms of oppression, particularly racism (Phillipson 1992:55). However, linguicism is different from other forms of discrimination in that, particularly due to language ideologies and symbolic violence, it is so normalized that we as social agents rarely recognize its existence (see e.g. Bourdieu \& Wacquant 1992; Lippi-Green 1997; Cashman 2006). Like cultural hegemony, language ideology contributes to the reproduction of social power in social fields (e.g. education, culture, country), and taken-for-granted power is 
concentrated in the dominant language speaker group(s) and their dominant culture, such as native English speakers in the US (see e.g. Fairclough 2001; May 2005).

Bourdieu's concept of symbolic violence extends Gramsci's hegemony (1971) and the concept of ideology — 'the system of ideas, beliefs, speech and cultural practice that operate to the advantage of a particular social group' (Mesthrie, Swann, Deumert, \& Leap 2000:320) — and, as Schubert (2002:1092) argues, Bourdieu affirms the idea that 'we engage in [the] processes of social construction in our everyday activities'. More specifically, minority languages such as Te Reo Māori might have significant cultural and group identity values (Wall 2003:125; May 2005:334), yet linguistic minorities often find political, economic, cultural, and social advantages in acquiring and speaking the dominant languages like English in New Zealand and become complicit with the language hegemony and domination (see Swartz 1997; Irvine \& Gal 1999). As a valuable form of capital, linguistic capital in this particular case is justified and legitimized through the process of symbolic violence, so the value of speaking dominant language(s) is determined upon the social agents' CONSENSUS rather than FORCE (Bourdieu \& Wacquant 1992:167; Swartz 1997:89). Thus, symbolic violence is explained as a 'system of circular relations that unite structures and practices; objective structures tend to produce structured subjective dispositions that produce structured actions which, in turn, tend to reproduce objective structure' (Bourdieu \& Passeron 1977:203). As a result, external structures are internalized in each agent through socialization and become 'habitus', which generates certain perceptions and practices, and these normalized practices reproduce the external structures as 'fields'. Thus, through symbolic violence, particular (even temporary) ideologies and hegemony are produced, reproduced, and fortified upon agents' consensus and everyday practices.

Unlike ascriptive characteristics such as race and sex, language is in principle achievable. Conversely, because the dominant language is taken for granted, linguistic minority immigrants and refugees sometimes internalize linguistic oppression and try to learn the dominant language to succeed in competitive education and labor markets in a host/migrating country (e.g. Pedraza 1996:11). Thus, it is unsurprising that, instead of promoting bi/multilingualism, an assimilationist approach is dominant in human services, including education systems, which serve immigrants and refugees and expect them to comply with the dominant language (Swartz 1997; Kissman 2001). Through symbolic violence - the process of developing their habitus complying with [in]formal rules in a host/migrating country, minority languages may perceivably become 'inferior' to the dominant languages and may even be stigmatized in their habitus (e.g. Bartolomé 2006:25). Language hierarchy becomes evident, and the status of one's language may affect one's self-esteem (Schmid 1992:206). Linguistic minorities, especially immigrants and refugees, are under constant pressure to linguistically assimilate to the host country/culture and may have constant feelings of anxiety and inferiority for not speaking the dominant languages well enough (see Bartolomé 2006; Woodrow 2006). Consequently, symbolic violence, along with other social factors such as race and sex, contributes 
to micro-level power inequality when linguistic minorities interact with native speakers.

Notably, there are multiple social fields, and linguistic minorities, especially migrants, develop linguistic landscapes ${ }^{3}$ or what Klinenberg (2002) terms social infrastructure (e.g. ethnic enclaves and ethnic networks) in which they preserve their culture and language, offer themselves economic, cultural, and social activities in their own languages, and avoid interactions with native speakers (Uekusa 2009:65-68). Some multilingual individuals can move across these different social fields because they have multiple habituses and packages of linguistic capital, which enable them to be legitimate members in different fields. In contrast, there are many individuals, such as more vulnerable linguistic minority immigrants, refugees, and transients, who do not have the specific linguistic capital and stay in limited linguistic landscapes due to the field-specific rules and laws (often manifested in language barriers), which become a major issue during emergencies when communication is vital (Donner \& Rodrígues 2008; Nepal, Banerjee, Perry, \& Scott 2012; Senkbeil, Scott, Guinazu-Walker, \& Rockman 2014). People may gradually learn the dominant language as they enter a new social field, but they cannot collect this form of linguistic capital overnight. Research shows that, in disasters, people become altruistic and bond by improvising, breaking traditional boundaries, such as race, class, religion, and language (see Casagrande, Mcllavine-Newsad, \& Jones 2015:353). Admittedly, it is still highly problematic if linguistic minorities do not understand disaster warnings and cannot communicate with authorities and with others in emergency situations.

\section{PREVIOUS RESEARCH ON LINGUICISM IN DIS ASTER CONTEXTS}

Disaster linguicism is an under-investigated theme both in disaster research and in language research even though communication is critical in emergency situations, and most disaster researchers recognize the issue of structural language barriers during life-threatening events and the immediate need to overcome this issue. Disaster research generally acknowledges that linguistic minority immigrants and refugees, despite often showing remarkable resilience (e.g. Klinenberg 2002; Leong, Airriess, Chen, Keith, Li, Wang, \& Adams 2007), are more vulnerable to disasters than their counterparts due to pre-existing structural inequalities (Donner \& Rodríguez 2008:1096). Indeed, previous disaster research has noted that 'language skills and literacy' are among the major contributing variables in many social vulnerability and resilience indices (e.g. Cutter, Boruff, \& Shirley 2003). In disasters, 'timely information is vital to the well-being of affected residents' (McKee 2014:107), and the role of language in diffusing disaster warnings and relief information is vital in disaster response, risk communication, and preparedness (see e.g. Peguero 2006; Arlikatti, Taibah, \& Andrew 2014; O’Brien, Federici, Cadwell, Marlowe, \& Gerber 2018). As Duncan (2013:10) argues, 
[f]oreign residents who do not read, understand, or speak the local language can be at a severe disadvantage during a disaster situation, and it can be readily predicted that they will become heavy consumers of information and advice from sources that use their native language.

This is evident in numerous studies such that, as Petri (2009:paragraph 4) explains, 'Hurricane Katrina hit Latinos harder than it hit other ethnic communities. Many Spanish-speaking Latinos did not even evacuate - almost all storm warnings were broadcast in English'. Similarly, '[t]he 30 deaths, most of them of Mexican descent which occurred in 1987 when an F4 tornado came down in Saragosa, Texas, are attributed to the failures of translating and transmitting the warning message into Spanish on time' (Aguirre 1988, quoted in Arlikatti et al. 2014:536). Linguistic barriers may not be the reasons for differential evacuation behaviors since many undocumented Latinos did not evacuate for other reasons in previous disasters (i.e. fear of arrest and deportation, hesitation over being visible and receiving aid, lower risk perceptions, nowhere to evacuate to) (see e.g. Petri 2009; Martinez \& Núñez-Álvarez 2017).

The paradox here is that, while human services and social work generally focus on teaching linguistic minorities the dominant language (Kissman 2001), the major solution to information access disparity in disaster response and mitigation is to diffuse information and provide services in multilingual formats, or through translators or computer-automated translation (see O'Brien et al. 2018:632). Tierney (2006:117) recognizes such efforts but still problematizes disaster-related language planning. ${ }^{4}$

Non-English speaking minorities experience a range of problems with respect to hazards and disasters [in the US]. Although some improvements have been made in making hazard-related information available in Spanish and some Asian languages, a large portion of detailed guidance is available only in English.

There has been much emphasis in making immediate and simplified disasterrelated information accessible in multiple languages, including sign languages, without sacrificing the amount and quality of information in the dominant language. Indeed, government services including emergency information and disaster signage are provided in 'easy Japanese' in Japan so that, to a certain extent, novice speakers can also understand (Carroll 2012; Gottlieb 2012; Tan \& Said 2015). However, this is different from overcoming disaster linguicism at the profoundest level by providing multilingual services and information, which would help linguistic minorities recover from and prepare for disasters at the same level and speed as native speakers and those with higher language competency (native speakers hereinafter).

Furthermore, I identified a major gap in the literature that micro-level disaster lingucism (also defined as interpersonal disaster linguicism) has not been properly addressed. Severe stress and heightened mental health issues among linguistic minorities during disastrous situations due to their limited linguistic capacity are evident (see e.g. Santos-Hernández \& Morrow 2013:265). Incidentally, there is a further gap in the literature as the emotional aspect of language in disaster is 
rarely emphasized. What researchers, policymakers, and practitioners have overlooked is that, in addition to the already known vulnerability factors such as race, class, and gender, linguistic minorities' disaster experiences might be affected by language ideology. Linguicism in disasters may be overlooked as it is usually institutionalized and compounded with other characteristics-race, lower socioeconomic status (SES), lower educational attainment, lack of local/cultural knowledge, and being transient-which limit linguistic minorities' ability to respond to and recover from disasters (Santos-Hernández \& Morrow 2013:273). Hence, investigating how linguistic minorities negotiate disaster linguicism and their everyday practice in emergency situations could give us a holistic picture of how we can simultaneously address and tackle the unsolved and unarticulated disaster linguicism both at structural (social field) and interpersonal (habitus) levels. Providing information in multilingual formats is certainly helpful, yet I argue that there is a strong need to explore and theorize disaster linguicism to address and solve the underlying issues beyond simple information access in disaster response and preparedness.

\section{RESEARCH METHODOLOGIES AND D A A C O L L E C T I O N}

In analyzing linguistic minorities' disaster experiences, I have drawn upon qualitative data and some empirical examples. I conducted twenty-eight in-depth interviews with linguistic minority immigrants and refugees, who experienced ${ }^{5}$ the 2010-2011 disasters and ongoing recovery in the region of Canterbury and in the prefecture of Miyagi. Their cultural and linguistic backgrounds are diverse (i.e. the participants are originally from Africa, Asia, Europe, the Middle East, the Pacific Islands, and South America, some of whom are novice in English/Japanese); thus, I included some service providers who supported this group and could speak for them. I am aware of the diversity among these groups and the many differences between these two locations, yet my focus is to explore some commonalities among linguistic minorities who are often considered to be socially vulnerable to disasters. Thus, instead of extensively comparing and contrasting the two groups of participants in Japan and New Zealand, I am more interested in emphasizing similarities and addressing the underlying issues around disaster linguicism. This approach enabled me to gather valuable information that detail-rich case studies do not offer (see Espiritu 1992 for the benefits of a panethnic approach like this).

Through my personal and professional networks and community organizations, I used convenient snowball sampling to recruit this relatively hard-to-reach group of respondents. Selection criteria were set to a minimum since it was difficult to recruit participants from these hard-to-reach groups. This was compounded by the fact that this research was conducted a few years following the disasters: (i) many had moved away, (ii) many had forgotten elements of their experiences, or (iii) many understandably did not want to revisit traumatic experiences. Furthermore, some linguistic minorities were 
hard to reach because they tried to invisibilize themselves and refrain from interacting with their ethnic networks in order to avoid racism and other forms of oppression, and for other political and religious reasons (see Villegas 2010; Koike 2011; Uekusa \& Lee 2018). Interviewees include both men and women (thirteen men and fifteen women) and various age groups (between their twenties and fifties) to ensure diverse voices. I conducted fifteen interviews in Canterbury and thirteen interviews in Miyagi. With the interviewees' permission, all of the interviews were recorded and conducted in English, Japanese, or Spanish without the assistance of interpreters. Except for some interviews in Japan, all of the interviews were conducted either in the interviewee's native language or the researcher's non-native language. This helped to at least minimize the power inequality (attributed to language ideology) between the researcher and the interviewees (see Uekusa 2009). All interviews were open-ended ${ }^{6}$ (rather than structured), so respondents were able to freely tell their stories after they were asked standard demographic questions.

Notably, many interviewees in both locations are 'marriage-migrant women' (see Uekusa \& Lee 2018) whose disaster experiences were largely shaped by the complex intersection of international gender and race politics (see e.g. Parreñas 2000). It is also noteworthy that, while the women in Canterbury married and migrated for affective reasons, marriage-migrant interviewees in the Tohoku rural areas married and migrated mainly for economic reasons. Unlike many of the female participants who were originally from countries such as China, Korea, and the Philippines and whose main motive for migration was to search for a better life, none of the male participants are marriage-migrants in this study. They had other reasons to migrate. Thus, the participants' disaster experiences are highly classed, gendered, and racialized. Although the focus in this article is on disaster linguicism, I have no intention of simplifying the significance of intersectionality for their disaster experiences.

\section{IN F ORMATION ACCESS ISS UES WHILE} RESPONDING TO THE DISASTERS

The experiences of the participants, both in Canterbury and Miyagi, confirmed their social vulnerabilities to disasters due to the lack of linguistic and other forms of capital. The intersection of race, class, gender, immigrant statuses, language, and many other contributing factors was highly evident. In the following sections, study findings are presented in a chronological order, categorized by disaster stages ${ }^{7}$ such as: (i) disaster response and immediate aftermath, (ii) short-term recovery, and (iii) long-term recovery and the new normal.

Structural or institutionalized disaster linguicism contributed to one of the most noticeable disadvantages that many of the study participants needed to deal with during the disasters and in the immediate aftermath. Previous empirical research concentrates on how language proficiency in de facto languages, such as English in New Zealand and Japanese in Japan, is a clear barrier to obtaining disasterrelated information (e.g. disaster warnings, disaster signage, preparedness, relief 
aid, recovery), which has placed linguistic minorities in vulnerable situations (Tierney 2006:117; Marlowe \& Bogen 2015:126). Linguicism makes critical disaster information, especially warning messages, inaccessible to certain people, and this can result in a higher likelihood of fatalities and devastating damage.

Participants in Miyagi explained their first-hand experiences, where critical information, such as tsunami warnings and evacuation information, was simply not accessible, particularly for newcomers who were not competent in Japanese. For instance, Maria, a Filipina marriage-migrant woman in Miyagi, told a story about her friend, another Filipina marriage-migrant woman who did not understand Japanese. During the life-threatening situation,

one of us perished in the tsunami... well, the thing is that she must have not understood the tsunami warning announcement because the announcement was in Japanese, you know? And the announcement was using these words that are not being used in everyday life.

It is possible that Maria's friend had other reasons why she failed to evacuate, but we can no longer ask her whether or not she understood the announcement in Japanese; as Maria asserts, linguicism appears to be the explanatory variable in this particular case. Meanwhile, Wei, a Chinese migrant woman involved in community service, also pointed out that "many Chinese marriage-migrant women could not communicate well during disasters... they understood hinan [to evacuate] but not what takadai [higher place] meant". While most Japanese speakers understood this simple message and acted accordingly, these immigrant women did not comprehend the tsunami warnings that they were supposed to evacuate to higher places. This might not have directly caused more fatalities, but there might have been confusion and possible delay in making an action (i.e. even if non-Japanese speakers, such as Filipina marriage-migrant women in this case, did not understand the warning, they might have seen others and evacuated accordingly). Thus, overwhelming evidence of these language barriers in life-threatening situations suggests the importance of diffusing disaster warnings, evacuation information, and disaster preparedness in multilingual formats and in simple language such as 'easy Japanese' (as technical language and jargon used in disaster warnings and recovery information are often problematic; see Christchurch Migrant Inter-Agency Group 2011, Carroll 2012, Gottlieb 2012, McKee 2014, Tan \& Said 2015).

\section{IS ASTER LINGUICISM IN SHORT-TERM RE C O VER Y}

In the short-term recovery stage, it may no longer be a matter of life and death; however, linguistic minorities continue to struggle in similar and different ways. Asad, a Somali refugee in Canterbury involved in community service, explained:

Obviously, we are resilient, we are not on our own. We can cope and recover... but we need support. The [New Zealand] government is very kind... but everything is in English, very important information is in English. Information first comes out in English... so even though they are trying hard... it's not multicultural enough... 
Although Asad did not clarify the type(s) of important information that they needed in their language, his frustration at not being able to obtain information as quickly and accurately as in English is obvious. As mentioned earlier, the Red Cross or other organizations provide the localized disaster education when refugees come to New Zealand, yet the education simply focuses on 'how to prepare for and respond to disasters' but not on 'how to cope with them or how to find and read related-information in English'.

Seo-yuun, a Korean migrant involved in community assistance in Canterbury, also pointed out the increase of perceived stress in Chinese and Korean communities due to disaster linguicism:

Even for [those] who live in the west side [of Christchurch] and weren't directly affected by the earthquakes, it was so stressful... our community, older Koreans or Chinese, because of the language barriers, the level of their stress was higher than Kiwis... lack of information, misunderstanding of the news or articles and everything...

Similar accounts were shared with me in Japan. Wei also described her frustration:

There are lots of things FOREIGNERS ${ }^{8}$ didn't understand. Important announcements were not in easy Japanese. While the Japanese understand everything immediately, for foreigners, there are lots of things they don't understand at evacuation centers. For example, where to go to get relief goods including food, where the first-aid stations are, where to get drinking water, where to get temporary housing information... While the Japanese have all this information, the foreigners knew nothing. In the coastal areas where there were many foreign wives whose husbands were washed away by the tsunami, these foreign wives found themselves in a situation where they could do nothing simply because they can't communicate in Japanese [emphasis mine].

We can certainly learn lessons from the experiences of linguistic minorities in previous disasters, and based on the accumulated knowledge, we can offer types of disaster information needed in multiple languages (e.g. tsunami warnings, where and how to get relief goods, food, water, first aid). However, although we cannot claim a solid conclusion based on these excerpts that linguistic minorities have actually experienced higher stress than native speakers after the disasters, it is likely that the issue may not just be the difficulty of understanding the key disaster terms and accessing critical information during disasters. As such, this can be conceptualized as a taken-for-granted 'capital or privilege' that native speakers are more likely to possess in disasters. Again, these linguistic minorities may not be purposefully discriminated against, yet their micro-level struggles due to linguicism are worth addressing in linguistic and disaster scholarships.

In the short-term recovery, many victims experience increased anxiety, depression, trauma, and other psychological issues, and not being able to communicate or not having someone to talk to about one's worries and concerns can negatively affect one's mental health (Santos-Hernández \& Morrow 2013). Mental health practitioners (e.g. Mental Health America 2016) often suggest that disaster survivors simply 'talk about it' as it is likely that being unable to express their true feelings after a disaster may cause posttraumatic stress disorder (PTSD) and other mental health issues. Voges \& Romney (2003) found that social support or 
simply having someone available to talk to about their trauma significantly lowers the likelihood of disaster survivors' developing PTSD. However, having someone available to talk to in native language(s) in disasters may be more difficult for some linguistic minority transients, especially if they are isolated.

For example, Takao, a Japanese pastor involved in supporting the Japanese exchange students in Canterbury, underlines the extreme importance of being able to communicate in emergency situations. Takao's lengthy recollection below demonstrates the profound need for linguistically diverse services in disaster situations.

[These Japanese exchange students who were in or near the collapsed buildings] didn't know their host families well yet, they didn't understand English at all... many of these severely injured young students were brought to the hospital and were panicking. The hospital staff just couldn't handle [them] because of the language barrier... The hospital needed help, they contacted some Japanese in Christchurch and found me. I rushed to the hospital. The hospital was in chaos... A nurse told me, 'there are many Japanese young students here who don't understand English and need help. I can't handle this all by myself'. There are five severely injured students then... It was awful. It was like a mixture of cultural shock and trauma... Everyone was screaming in Japanese... nurses didn't understand them. 'I've never seen and can't eat this!', 'What's in this syringe? I don't know what's inside, I don't want to get that shot!' and so on... It was horrible. Well, I talked to the students in Japanese and gave them some Japanese food. I felt a great relief... they calmed down. Their host families also felt relieved. I felt sorry for the host families too... They didn't understand each other because of the language barriers... They wanted to show their compassion and support the injured students, but they couldn't communicate.

Takao added, "I think it was good that I was able to talk to them in the same language. If there hadn't been a person who could speak Japanese, what would have happened to these Japanese students? I can't even imagine". Besides the obvious lack of predisaster arrangement at the hospital and other sociological issues presented in this excerpt, the main point emphasized in this unexpected emergency situation is the need for the Japanese students, who have very limited linguistic and social capital, to be able to communicate, which English speakers took for granted.

This is similar to marriage-migrant women in Miyagi. Maria explained:

After the tsunami, since most of [Filipinas] lost houses, they lost everything actually... just like me. So, they needed materials. But first, we needed someone to talk to. When they felt lonely, they come to me, so I say 'just wait outside, I will be there in a minute', so we tried to eat lunch together, and they want... you know, bring out their worries in Tagalog, they have burdens in their heart, and they are very much confused about what they were going to do because they can't understand Japanese.

Clearly, the main concern has been how to diffuse disaster warnings to linguistic minority communities and provide human services in multiple languages; these excerpts reiterate that the emotional aspects of language in disaster contexts, particularly after the first-response period, should not be overlooked. Emotional support or, as Takao and Maria point out, simply having someone to talk to in their native languages, which English and Japanese speakers took for granted in these particular locations, might be the immediate need of disaster survivors, especially among transients and isolated marriage-migrant women. Despite the increased community cohesion and altruism in the 'honeymoon' disaster period that removes traditional social barriers, including language (Casagrande et al. 2015), 
the extended support system and altruism may simply be inaccessible to some linguistic minorities.

Unlike the abovementioned cases in which discriminators may not necessarily be present, symbolic violence might allow native speakers to legitimately or subconsciously practice interpersonal-level linguicism, which exacerbates linguistic minorities' disaster vulnerability and complicates the promotion of multilingual communications in emergency situations. Kayo, a disaster support center staff in Miyagi, explained a case that she observed:

\begin{abstract}
When we were asked to visit local evacuation centers and check on foreign nationals, there are many marriage-migrant women who didn't want to identify themselves as foreigners as they had tried to integrate. We could SEE Filipinas but usually we can't distinguish Chinese and Koreans, they LOOK LIKE Japanese. Their husbands and families don't want to tell others that their wives are from China or Korea. So, we were looking for them but could not loudly make announcements to find them because it caused a great discomfort for them and their families. Even if we find them, we could not physically separate these women from their husbands and families and talk in their native languages other than Japanese, which their family members did not understand. Their husbands and parents-in-law feel insecure and suspicious if their foreign wives [and daughters-inlaw] are talking to us in languages that they don't understand... so we needed to be very cautious [emphasis mine].
\end{abstract}

Kayo's observation reiterates the notion of communication disparity (besides many other sociological interests): It is justifiable that these marriage-migrant women do not understand what their family members talk about in Japanese, yet it is not acceptable that their family members do not understand what these migrant wives speak of in their own languages. As previously discussed, being able to communicate in one's native language(s) or any language that one feels comfortable with during a frightening or stressful time should not be considered a privilege. As noted, unreasonable sanctions and punitive responses often come from native speakers (mostly host families and communities) who are apparently unaware of the power inequality and linguicism. Thus, multilingual communication might appear simple if we do not carefully look into their circumstances.

\title{
D I S A T T R L I N G U I C I M IN L O N G - T E R M RECOVERY A N THE NEW NORM A L
}

As the recovery progresses, many victims go back to a 'new normal', their experience of disaster linguicism becomes more recovery-related and is very much like dealing again with 'everyday linguicism'. In particular, additional psychological burdens and the possibility of additional economic loss due to micro-level disaster linguicism was evident in some of the participants' experiences as, for example, in dealing with insurance settlements in Canterbury. In the following instances, linguistic minorities endured the 'pain' and internalized the linguistic oppression in addition to those disaster-related struggles they had already confronted like many others. One of the Women's Voices project (Christchurch Branch of National Council of Women of NZ 2014:5) interviewees, Hana, a Korean migrant woman in Canterbury, expressed her anger and the perceived linguistic and psychological 
disadvantages she faced when dealing with a coercive insurance company in English.

I don't want to argue with my insurance company. I felt kind of disadvantaged with my lack of English skills, so my family decided the easy option... we accept [the] Government's offer, Option 1 [instead of negotiating a settlement on their house with the insurance company]. I don't have the confidence with the language, so I gave up.

Even if recovery and relief information is provided in multilingual formats by authorities and community organizations, it is different from supporting and empowering Hana to negotiate with native speakers when she felt linguistically disadvantaged. She had to bear the feeling of inferiority and, to a certain extent, being taken advantage of; she internalized linguistic oppression. Similarly, Chie, a Japanese immigrant woman married to a New Zealander in Canterbury, explained her observation of disaster linguicism that her friends and Japanese families have gone through.

The EQC [Earthquake Commission] and insurance companies look down on Japanese... they are not serious... When Japanese are told to sign the insurance settlement, they just sign without questioning. We don't really understand English and we can't really negotiate, so we just sign without asking... If the EQC says, they did all the necessary repairs, they trust it and signed the settlement. When they are offered a specific amount of money and asked to sign, they can't really challenge the EQC.

Settlement with insurance companies is often time-consuming and difficult even for native speakers because, beside language hegemony, power inequality during negotiations may also be attributed to gender, race, nationality, and other factors. However, in this excerpt, the perceived linguistic disadvantage, which native speakers normally do not have to confront, is obvious (see also Leong et al. 2007). Although the Japanese cultural norm of being nonconfrontational might have negatively played a role in this case, it is important to address their feelings of inferiority and being taken advantage of due to the intersection of micro-level linguicism and other forms of oppression, especially gender and racial discrimination among many of the study participants.

Internalizing everyday linguistic oppression results in lower self-esteem and confidence to negotiate, which could exacerbate linguistic minorities' social vulnerability, particularly in long-term recovery. This can be a major reason why even if government services are available to them, many of them have limited confidence to ask for disaster relief aids and recovery information, which are part of their fundamental human rights. Krishna, an Indian immigrant involved in community assistance in Canterbury, explained:

\footnotetext{
Well, the challenges facing migrants are... there is [an] access to information issue. They don't know where to go, they don't know who to go to, they don't have any time to find information because they are too busy with this new place... they don't know that there are a lot of things available to them. Because of the lack of English, I am speaking for the non-English speaking background migrants here, they don't have the confidence to just walk into social services or someone to ask for help, telling them 'this is what I need', even have the confidence to stop a Kiwi and say, 'Excuse me, where do I go for this? You know how to get to this place?' or whatever. It's not because they can't do it, because, in new [a] country, they don't have the confidence... a lot of times, they believe that their English is really bad, so they don't say anything.
} 
Speaking for his clients and communities, Krishna emphasized that people's lack of confidence, in addition to certain cultural attributes/norms, hinder them from asking for help during a disaster, which can have devastating consequences as people may lose (or temporarily lose access to) their own assets, and they usually need external help to get by.

It has been noted that the struggles that the participants of this study, who belong to a linguistic minority, confronted in the disasters did not only occur during the disasters themselves. The study of how linguistic minorities experience disaster linguicism should begin with an examination of their experiences prior to the actual disasters because for THEM, linguicism is not new. My interviews revealed that, as the victims were going back to the new normal, linguicism returns as an everyday social phenomenon, whereas many of us might have only noticed it during or after the disasters due to VISIBLE language barriers. Structural efforts to resolve language barriers in disasters have been made (i.e. multilingual disaster warnings and relief information services, bi/multilingual volunteers), but these should not be temporary efforts. In this regard, Takeshi, a multilingual disaster support center staff in Miyagi, pointed out:

Not just during the emergencies... in our everyday work, we know that communication is difficult because of the language barriers... We already know this. Something difficult like communication with foreign nationals in a non-emergency can become more difficult in [an] emergency. All the infrastructure[s] getting disrupted and the Fukushima disaster were unexpected... but the foreigners' struggles were predictable...

Admittedly, the language barriers existed prior to, and will continue to exist after, the disasters. As Takeshi confirmed, it is predictable that ordinary communication difficulties due to the lack of linguistic capital can be worse in emergency situations. Considering this, the society, particularly the government, should exert more effort in solving everyday linguicism as part of disaster risk-reduction strategies. Authorities and foreigner support organizations, such as that of Takeshi's, obviously work to solve the language barriers, but most efforts concentrate on simply providing information in multilingual formats and not on understanding the hidden injuries of, and root causes of, disaster linguicism. Therefore, the participants' everyday experiences of linguicism or linguicism in the new normal are briefly presented to further contextualize them in the disasters.

When asked about her life difficulties after the disasters, Laura, an Argentinean migrant woman married to a New Zealander living in Canterbury, explained her feeling of linguistic disadvantage and her frustration at having to communicate in English.

Language is the one, you know? My accent is not good, so sometimes it's very difficult to communicate with people... even [when] I understand and I have been living here twelve or thirteen years, I still can't get rid of my accent... sometimes I don't know how to improve that. I have been taking some lessons but... because of my accent and different way of speaking, sometimes even [if] I have good qualifications, I do not have the same opportunity to get a job in New Zealand. It's frustrating... 
Unlike some marriage-migrants from Asia in this study, Laura is a middle-class Caucasian, who married and migrated to New Zealand for affective reasons. Hence, it may be less appropriate to employ the feminization of migration framework to analyze her narrative since language ideology and symbolic violence are the central concerns here. Although her English competency might not have caused actual employment disadvantages, her feelings of frustration and possible internalization of perceived linguistic oppression in her everyday and postdisaster life cannot be ignored.

Laura's frustration tends to come from the underlying communication disparity between native speakers and non-native speakers rather than linguistic minorities' INCONVENIENCE. As such, there is a need to emphasize communication equality in disasters because disparity in communication might cause additional psychological burdens - HIDDEN INJURIES that linguistic minorities have to deal with - instead of the inconvenience of not understanding the disaster warnings as quickly and as accurately as native speakers. Linguistic minorities may confront linguicism without actual discriminators, yet they are constantly exposed to symbolic violence such that the internalization of linguistic oppression is difficult to avoid.

Another common everyday experience of linguicism revealed in the interviews was that of social exclusion and isolation due to language barriers. Wei identified a common experience among Chinese marriage-migrant women in Miyagi.

\footnotetext{
If Chinese wives speak Japanese well enough, it's fine. But there are many Chinese wives who have been here for a long time but don't understand Japanese well enough... especially for those older wives who came to Japan when they are older... there are many foreign wives who have hardships in their own countries and came to Japan to restart their life when they are in their thirties or forties or even fifties. These women, even after ten years, have [a] difficult time understanding Japanese. They don't speak Japanese well enough and [they] live in rural communities... they are often ignored and isolated.
}

In addition, Rie, a Korean marriage-migrant woman in Miyagi, described her feeling of loneliness and exclusion due to linguistic isolation prior to, and after, the disasters.

I feel excluded because of the language. For example, my husband's younger brother... he has four brothers, and his younger brother lives in Sendai, and they sometimes come here. His wife of course speaks Japanese, but I don't really speak Japanese... so if I tried to be a part of [the] conversation, I feel like I interrupt and make them uncomfortable... they always say, 'we don't mind' but I know they have to stop their conversation if I interrupt... I have a lot of things and worries, I want to talk to someone...

Although this article does not aim to study the respondents' everyday experiences of linguicism, it is possible that chronic feelings of linguistic exclusion contribute to their isolation and everyday oppression (see also Leong et al. 2007). Hence, it is important to understand that these may be the true everyday feelings of isolated linguistic minorities living in foreign countries, where their native languages are not spoken. 
A major misconception in disaster research is the notion that disaster linguicism suddenly emerges during disasters. Many of the study's participants noted that linguicism is a consistent form of social discrimination, which exists in their everyday life in the host countries. Linguicism might have only become visible to the public during these disasters, but for them, it is nothing new. As such, overcoming disaster linguicism might require proper investigation of linguistic minorities' everyday experiences of linguicism. As Maria, who teaches English to Japanese, and Japanese to newcomers from the Philippines in Miyagi, mentioned, teaching Japanese is empowering for these marriage-migrant women. However, this illuminates an underlying issue: They not only need to bear feelings of inferiority and linguistic oppression, they are also made to feel responsible for their limited language competency. Due to symbolic violence, language ideologies are normalized and unquestioned. Along with classed, gendered, and racialized oppression, this often silences linguistic minorities, especially marriage-migrant women and other marginalized people, and it discourages them from asking for specific support even in emergency situations just because some of them do not feel comfortable and confident to speak in English or Japanese.

If linguistic minorities are hard-to-reach, such as the marriage-migrant women in Tohoku (Uekusa \& Lee 2018) and undocumented immigrants in the US (Villegas 2010) who invisibilize themselves for better prospects and to avoid racial profiling and its sanctions, they are unlikely to receive disaster relief aid unless they actively reach out and ask for help. In this regard, I align my findings with Klinenberg's (2002:129-64) Chicago heat-wave study, which assert that governments and authorities often fail to understand disaster survivors' vulnerabilities and to recognize the immediate need of intervention (see also Campbell 2018). For vulnerable linguistic minorities, not being able to ask for specific help can mean not receiving it; not being able to narrate their own experience in their own language can mean not being heard. Without understanding their experiences of disaster linguicism, linguistic minorities are often made responsible for their own fate.

Native speakers, particularly service providers, tend to ignore their privileged circumstances and the structural oppression that they may unwittingly perpetuate. Indeed, Keiko, a disaster support center staff in Miyagi, argued that foreigners in Japan should be responsible for their own recovery.

I know a Brazilian woman, after [the] disaster she didn't know what to do and she was so scared that all the time she was staying in the house, she ate and drank all the food and water she had... didn't know what to do next... We didn't know what to do either. They must come outside and ask for help. If there is no one around, go to the place her husband works or to her children's school teachers. You must approach somebody. That's why 'self-help' is important. I sympathize deeply with this Brazilian woman, she didn't speak Japanese, she couldn't read information and felt completely lost. I do sympathize. But, as someone said, she should have stood up, opened the door and made a step outside. 
Although Keiko played an important role in supporting foreigners in the Tohoku disasters, her account underlines the typical responsibilization of victims approach, which offers little consideration of their circumstances (see Rose 1999 for the concept of responsibilization). Some linguistic minorities, especially those who are more vulnerable such as marriage-migrant women, are blamed for not asking for help even in emergency situations. However, instead of 'responsibilizing' them, what is missing in the typical discussion on supporting foreigners is the understanding of linguistic minorities' disaster experiences from THEIR perspectives. It is probable that, as Krishna also observed, this Brazilian marriage-migrant woman's low self-esteem and lack of confidence to communicate with native Japanese speakers in Japanese might have been caused by everyday linguistic oppression, in addition to her traumatic disaster experiences. Conversely, most service providers and even researchers seem to disregard this.

An important theoretical implication for future research is that, although linguistic minorities are often considered powerless victims in disasters due to disaster linguicism, it is crucial to regard their agency. They are strategic and rational improvisers who generate and use various forms of capital, particularly social capital (Bourdieu 1986), and actively deal with disaster linguicism. This is an area that requires further investigation. Despite their significant disadvantages and governments' failure to provide proper support, many linguistic minorities are resilient to disaster linguicism and do not give up when dealing with linguicism in emergency and everyday situations. In fact, their resilience to disaster linguicism does not come as a surprise as they deal with linguicism every day, using active and rational strategies, such as developing their own linguistic landscapes (see e.g. Pedraza 1996; Uekusa 2009). Marlowe \& Bogen (2015) found that even if the first (and second) generation refugees in Christchurch have limited English competency, their multilingual children play a significant role in helping their families get by and communicate with others (e.g. government agencies, local organizations, neighbors) in the Canterbury disasters. As children of immigrant families often help their parents to live in host countries (Portes \& Hao 2002), multilingual children can play a significant role in coping with disaster linguicism in the Canterbury disasters (e.g. Marlowe \& Bogen 2015). In this specific instance, parents who lack linguistic capital are able to use their social capital to take advantage of their children's linguistic capital. Their social capital includes their friends, families, and acquaintances. These forms of social capital are later converted into linguistic capital (see Bourdieu 1993 for capital conversion).

This study has explored and analyzed linguistic minorities' complex disaster experiences in the 2010-2011 Canterbury and Tohoku disasters and finds that they confront unique disaster vulnerability, partly due to linguicism. Although the study does not extensively emphasize their coping mechanisms and offer concrete policy discussions, it reiterates what has been missing in disaster research, practice, and policymaking. These respondents seemingly internalized linguistic oppression, complying with symbolic violence and reproducing language ideologies, and these 
disaster survivors may be reminded of their powerlessness and the need and importance of learning the dominant language. Thus, further examination of interpersonal-level disaster linguicism would present a clearer picture of why we need to explore linguistic minorities' everyday practice and protect them in disasters through more innovative ways than simply providing information in multilingual formats. Further research, which employs greater inclusivity, bottom-up approaches, and practical theories, will be crucial if we are to properly understand disaster linguicism and address the issues that confront linguistic minorities in disasters. This will offer critical, practical, and realistic policy insights for the development of more effective disaster management plans, disaster risk-reduction strategies, disaster language planning, and ultimately linguistic minority community empowerment.

\section{N O T E S}

*I would like to thank the two anonymous reviewers, the journal editorial team, and Dr. Jenny Cheshire for their time to review this article and provide valuable comments and constructive feedback. I would also like to thank the study participants in this study and acknowledge Dr. Steve Matthewman for his helpful suggestions.

${ }^{1}$ Sociologists of disasters do not use the term natural disasters. They discuss natural hazards (like floods and earthquakes), but disasters are a consequence of social arrangements, that is, how well a society copes with a natural or Anthropogenic hazard event.

${ }^{2}$ Miyagi Prefecture is one of the six prefectures in Tohoku, located on the Pacific coast, and its coastal communities have been severely affected by the tsunami.

${ }^{3}$ While in this article, I refer to social spaces, the concept of linguistic landscape in linguistics refers to the visibility of language and its symbolic function (Landry \& Bourhis 1997).

${ }^{4}$ Language planning refers to 'deliberate efforts to influence the behavior of others with respect to the acquisition, structure, and functional allocations of their language codes' (Cooper 1989:45).

${ }^{5}$ Disaster experiences are highly subjective, so I did not want to impose my categories upon the respondents in terms of disaster experience. Some were first responders, some lost their loved ones, some lost their homes, assets, and so on.

${ }^{6}$ Instead of using (semi)structured interview questions, respondents were asked open-ended questions, and they freely narrated their disaster experience. All transcription and translation was performed by the author before qualitatively analyzing the interview data. Pseudonyms are used in the analysis.

${ }^{7}$ While previous research concretely conceptualizes the disaster phases and cycle, I treat it as a subjective concept. Some people, especially less affected and less vulnerable, can exit from the response stage and recovery from disasters more quickly than the socially vulnerable.

${ }^{8}$ The term foreigner is generally used in Japan to describe non-Japanese nationals, instead of immigrants, refugees, linguistic minorities, or other common terms.

\section{R E F E R E N C E S}

Aguirre, Benigno E. (1988). The lack of warnings before the Saratoga tornado. International Journal of Mass Emergencies and Disasters 6(1):65-74.

Arlikatti, Sudha; Hassan A. Taibah; \& Simon A. Andrew (2014). How do you warn them if they speak only Spanish? Challenges for organizations in communicating risk to Colonias residents in Texas. Disaster Prevention and Management: An International Journal 23(5):533-50. 


\section{SHINYA UEKUSA}

Bartolomé, Lilia I. (2006). The struggle for language rights: Naming and interrogating the colonial legacy of 'English only'. Human Architecture: Journal of the Sociology of Self-Knowledge 4:25-32.

Benton, Richard A. (2015). Perfecting the partnership: Revitalizing the Māori language in New Zealand education and society 1987-2014. Language, Culture and Curriculum 28(2):99-112.

Bourdieu, Pierre (1986). The forms of capital. In John G. Richardson (ed.), Handbook of theory for the sociology of education, 241-58. New York: Greenwood Press.

(1991). Language and symbolic power. Cambridge, MA: Harvard University Press.

(1993). Sociology in question. London: SAGE.

- , \& Jean-Claude Passeron (1977). Reproduction in education, society and culture. London: SAGE.

— \& Loïc J. D. Wacquant (1992). An invitation to reflexive sociology. Chicago: University of Chicago Press.

Campbell, Ben (2018). Communities in the aftermath of Nepal's earthquake. In Louise Bracken, Hanna Ruszczyk, \& Tom Robinson (eds.), Evolving narratives of hazard and risk: The Gorkha earthquake, Nepal, 2015, 109-123. London: Palgrave Macmillan.

Carroll, Tessa (2012). Multilingualism or easy Japanese? Promoting citizenship via local government websites. In Nanette Gottlieb (ed.), Language and citizenship in Japan, 193-216. London: Routledge.

Casagrande, David G.; Heather McIlvaine-Newsad; \& Eric C. Jones (2015). Social networks of helpseeking in different types of disaster responses to the 2008 Mississippi River floods. Human Organization 74(4):351-61.

Cashman, Holly M. (2006). Who wins in research on bilingualism in an anti-bilingual state? Journal of Multilingual and Multicultural Development 27(1):42-60.

Christchurch Branch of National Council of Women of NZ (2014). Women's voices: Recording women's experiences of the Canterbury earthquakes. University of Canterbury Quakestudies. Online: https://quakestudies.canterbury.ac.nz/store/collection/228.

Christchurch Migrant Inter-Agency Group (2011). Lessons learned following the earthquakes of 22 February 2011. Christchurch Migrant Inter-Agency Network. Online: https://quakestudies.canterbury.ac. nz/store/object/21303.

Collins, Patricia H. (2000). Black feminist thought. New York: Routledge.

Cooper, Robert L. (1989). Language planning and social change. Cambridge: Cambridge University Press.

Cutter, Susan L.; Bryan J. Boruff; \& Lynn W. Shirley (2003). Social vulnerability to environmental hazards. Social Science Quarterly 84(2):242-61.

Donner, William, \& Havidán Rodríguez (2008). Population composition, migration and inequality: The influence of demographic changes on disaster risk and vulnerability. Social Forces 87(2):1089-114.

Duncan, Howard (2013). Immigrant integration as a factor in disaster preparedness: The case of the 2011 Tohoku earthquake in Japan. Migration Policy Practice 3(2):9-14.

Espiritu, Yen L. (1992), Asian American panethnicity: Bridging institutions and identities. Philadelphia, PA: Temple University Press.

Fairclough, Norman (2001). Language and power. London: Longman.

Gramsci, Antonio (1971). Selections from the prison notebooks. New York: International Publishers.

Gottlieb, Nanette (2012). Language policy in Japan; The challenge of change. Cambridge: Cambridge University Press.

Hakuta, Kenji (1986). Mirror of language: The debate on bilingualism. New York: Basic Books.

Irvine, Judith T., \& Susan Gal (1999). Language ideology and linguistic differentiation. In Paul V. Kroskrity (ed.), Regimes of language: Ideologies, politics and identity, 33-79. Santa Fe, NM: School of American Research Press.

Kazama, Motoki, \& Toshihiro Noda (2012). Damage statistics (Summary of the 2011 off the Pacific Coast of Tohoku Earthquake damage). Soils and Foundations 52(5):780-92. 


\section{DISASTER LINGUICISM}

Kissman, Kris (2001). Deconstructing the journey from assimilation to acculturation in academia. International Social Work 44(4):423-32.

Klinenberg, Eric (2002). Heat wave: A social autopsy of disaster in Chicago. Chicago: University of Chicago Press.

Koike, Katsunori (2011). Forgotten and unattended: Refugees in post-earthquake Japan. Forced Migration Review 38:46-47. Online: http://www.fmreview.org/technology/koike.html.

Landry, Rodrigue, \& Richard Y. Bourhis (1997). Linguistic landscape and ethnolinguistic visibility: An empirical study. Journal of Language and Social Psychology 16:23-49.

Leong, Karen J.; Christopher Airriess; Angela Chia-Chen Chen; Verna Keith; Wei Li; Ying Wang; \& Karen Adams (2007). From invisibility to hypervisibility: The complexity of race, survival, and resiliency for the Vietnamese-American community in Eastern New Orleans. In Kristin A. Bates \& Richelle S. Swan (eds.), Through the eyes of Katrina: Social justice in the United States, 171-88. Durham, NC: Carolina Academic Press.

Lippi-Green, Rosina (1997). English with an accent: Language, ideology, and discrimination in the United States. London: Routledge.

Marlowe, Jay, \& Rachel Bogen (2015). Young people from refugee backgrounds as a resource for disaster risk reduction. International Journal of Disaster Risk Reduction 14:125-31.

Martinez, Konane M., \& Arcela Núñez-Álvarez (2017). Empowered action during disasters: Disaster preparedness among migrant farmworker communities in the United States. In Lorenzo Guadagno, Mechthilde Fuhrer, \& John Twigg (eds.), Migrants in disaster risk reduction: Practices for inclusion, 41-56. Online: https://publications.iom.int/system/files/pdf/migrants_in_drr.pdf.

May, Stephen (2005). Language rights: Moving the debate forward. Journal of Sociolinguistics 9 (3):319-47.

McKee, Rachel (2014). Breaking news: Sign language interpreters on television during natural disasters. Interpreting 16(1):107-30.

Mesthrie, Rajend; Joan Swann; Ana Deumert; \& William L. Leap (2000). Introducing sociolinguistics. Edinburgh: Edinburgh University Press.

Mental Health America (2016). Coping with disaster. Mental Health America. Online: http://www.mentalhealthamerica.net/conditions/coping-disaster.

Ministry of Justice (2013). Registered foreign nationals by the country of origins, residing in the areas affected by the Great East Japan Disaster [translation mine]. The Ministry of Justice. Online: http:// www.moj.go.jp/nyuukokukanri/kouhou/nyuukokukanri01_00019.html.

Nepal, Vishnu; Deborah Banerjee; Mark Perry; \& Deborah Scott (2012). Disaster preparedness of linguistically isolated populations: Practical issues for planners. Health Promotion Practice 13(2):26571.

O'Brien, Sharon; Federico Federici; Patrik Gadwell; Jay Marlowe; \& Brian Gerber (2018). Language translation during disasters: A comparative analysis of five national approaches. International Journal of Disaster Risk Reduction 31:627-36.

Otani, Junko (2016). Earthquake insurance and post-disaster housing in the case of Canterbury earthquakes in New Zealand. Osaka Human Sciences 2:1-20. Online: https://ir.library.osaka-u.ac.jp/ repo/ouka/all/56909/ohs_02_001.pdf.

Parreñas, Rhacel S. (2000). Migrant Filipina domestic workers and the international division of reproductive labor. Gender \& Society 14(4):560-80.

Pedraza, Silvia (1996). Immigration, race and ethnicity in American history. In Silvia Pedraza \& Ruben G. Rumbaut (eds.), Origins and destinies: Immigration, race and ethnicity in America, 1-20. Albany, NY: Wadsworth.

Peguero, Anthony A. (2006). Latino disaster vulnerability: The dissemination of hurricane mitigation information among Florida's homeowners. Hispanic Journal of Behavioral Sciences 28(1):5-22.

Petri, Carolyn (2009). Translating disaster. The American Prospect. Online: http://prospect.org/article/ translating-disaster.

Phillipson, Robert (1992). Linguistic imperialism. Oxford: Oxford University Press. 


\section{SHINYA UEKUSA}

Portes, Alejandro, \& Lingxin Hao (2002). The price for uniformity: Language, family and personality adjustment in the immigrant second generation. Ethnic \& Racial Studies 25(6):889-912.

Potter, Sally H.; Julia S. Becker; David M. Johnston \& Katelyn P. Rossiter (2015). An overview of the impacts of the 2010-2011 Canterbury earthquakes. International Journal of Disaster Risk Reduction 14(1):6-14.

Rose, Nikolas (1999). The power of freedom. Cambridge: Cambridge University Press.

Santos-Hernández, Jennifer M., \& Betty H. Morrow (2013). Language and literacy. In Deborah S. K. Thomas, Brenda D. Phillips, William E. Lovekamp, \& Alice Fothergill (eds.), Social vulnerability to disasters, 265-80. Boca Raton, FL: CRC Press.

Schmid, Carol L. (1992). The English only movement: Social bases of support and opposition among Anglos and Latinos. In James Crawford (ed.), Language loyalties, 202-208. Chicago: University of Chicago Press.

(2001). The politics of language: Conflict, identity and cultural pluralism in comparative perspective. New York: Oxford University Press.

Schubert, Daniel J. (2002). Defending multiculturalism: From hegemony to symbolic violence. American Behavioral Scientists 45:1088-102.

Senkbeil, Jason C.; David A. Scott; Pilar Guinazu-Walker; \& Meganne S. Rockman (2014). Ethnic and racial differences in tornado hazard perception, preparedness, and shelter lead time in Tuscaloosa. The Professional Geographer 66(4):610-20.

Skutnabb-Kangas, Tove, \& Robert Phillipson (1995). Linguistic human rights, past and present. In Tove Skutnabb-Kangas \& Robert Phillipson (eds.), Linguistic human rights: Overcoming linguistic discrimination, 71-110. Berlin: Mouton de Gruyter.

Statistics New Zealand (2013). 2013 Census tables about a place: Canterbury region. Statistics New Zealand. Online: http://www.stats.govt.nz/Census/2013-census/datatables/tables-about-aplace.aspx? request_value $=24491 \&$ reportid $=14 \&$ tabname $=$ Culturaldiversity .

Suzuki, Eriko (2012). Higashi-Nihon Daishinsai ga tou tabunka-shakai, Nihon ['The Great East Japan Earthquake and Tsunami challenges Japan as a multicultural county']. In Hiroshi Komai \& Eriko Suzuki (eds.), Higashi-Nihon Daishinsai to gaikokujin ijyusha tachi ['The Great East Japan Disasters and immigrants'], 9-32. Tokyo: Akashi Shoten.

Swartz, David (1997). Culture \& power: The sociology of Pierre Bourdieu. Chicago: University of Chicago Press.

Tan, Mei S., \& Selim B. Said (2015). Linguistic landscape and exclusion: An examination of language representation in disaster signage in Japan. In Rani Rubdy \& Selim B. Said (eds.), Conflict, exclusion and dissent in the linguistic landscape, 145-69. London: Palgrave Macmillan.

Tierney, Kathleen (2006). Social inequality, hazards, and disasters. In Ronald J.Daniels, Donald F. Kettl, \& Howard Kunreuther (eds.), On risk and disaster: Lessons from Hurricane Katrina, 109-28. Philadelphia: University of Pennsylvania Press.

Train, Robert W. (2007). Language ideology and foreign language pedagogy. In Dalila Ayoun (ed.), French applied linguistics, 238-69. Amsterdam: John Benjamins.

Uekusa, Shinya (2009). Everyday experiences of linguicism: A sociological critique of Linguistic Human Rights (LHRs). San Marcos: California State University San Marcos, MA Thesis. Online: http://hdl.handle.net/10211.3/122624.

— \& Sunhee Lee (2018). Strategic invisibilization, hypervisibility and empowerment among marriage-migrant women in rural Japan. Journal of Ethnic and Migration Studies, 1-18 Online: https:// doi.org/10.1080/1369183X.2018.1500885.

Villegas, Francisco J. (2010). Strategic in/visibility and undocumented migrants. In George J. Sefa Dei \& Marlon Simmons (eds.), Fanon \& education: Thinking through pedagogical possibilities, 147-70. New York: Peter Lang.

Voges, Marcia A., \& David Romney (2003). Risk and resiliency factors in posttraumatic stress disorder. Annals of General Hospital Psychiatry 2:4. Online: https://www.ncbi.nlm.nih.gov/pmc/articles/ PMC162164/. 
Wall, Catherine E. (2003). Bilingualism and identity in Julia Alvarez's poem 'Bilingual Sestina'. MELUS (the Multi-Ethnic Literature of the United States) 28(4):125-43.

Woodrow, Lindy (2006). Anxiety and speaking English as a second language. RELC Journal 37(3):308-28.

(Received 4 April 2018; revision received 26 October 2018; accepted 21 December 2018; final revision received 22 December 2018)

Address for correspondence:

Shinya Uekusa

Department of Sociology, University of Auckland

Human Science Building, Level 9

10 Symonds Street

Auckland 1010, New Zealand

suek456@aucklanduni.ac.nz 